\title{
Increased Pulmonary Venous Resistance in the Critically Ill Patients
}

\author{
Charles Her* \\ Department of Anesthesiology, New York Medical College, USA
}

Submission: August 01, 2018; Published: August 13, 2018

*Corresponding author: Charles Her, Department of Anesthesiology, Westchester Medical Center, Valhalla, New York, USA, Tel: 914-715-4926;

Email: charles6133@msn.com

\section{Abstract}

In patients with sepsis, the presence of radiographic evidence of pulmonary edema may not necessarily indicate the fluid overload. The increased pulmonary venous resistance by endotoxemia can develop pulmonary edema in the absence of left ventricular volume overload. Development of pulmonary edema in this situation can contribute to less aggressive efforts of intravascular volume expansion, thus leading to hypovolemia.

A previous study examined risk factors and clinical outcomes associated with Transfusion-Associated Circulatory Overload (TACO), using the NHSN TACO Definition 2016 to identify cases of TACO, without defining the intravascular volume status. The problem is that most of criteria in NHSN TACO Definition 2016 could be explained by the increased pulmonary venous resistance rather than by TACO. In many cases there were probably no TACO. Interestingly, more patients in TACO group in that study had been on $\beta$-adrenergic blocker preoperatively, which increases pulmonary venous resistance by blocking $\beta_{2}$-adrenergic vasodilating effect. Inhalation of Salmeterol may prevent acute pulmonary edema by decreasing pulmonary venous resistance. The low pulmonary venous resistance would keep the lung water low.

Likewise, possibility that the radiographic appearance of pulmonary edema by the increased pulmonary venous resistance, despite the absence of the left ventricular overload, could have contributed to less aggressive efforts of intravascular volume expansion, thus leading to hypovolemia in many cases of Sepsis-3 Definition, cannot be excluded. In conclusion, without considering the possible presence of the increased pulmonary venous resistance and/or monitoring intravascular volume status, the validation of any definition regarding circulatory overload or sepsis is questionable.

Keywords: Pulmonary edema; Pulmonary venous resistance; Endotoxemia; Acute respiratory distress syndrome; Pulmonary venoconstriction; Transfusion associated circulatory overload

Abbreviations: TACO: Transfusion Associated Circulatory Overload; NHSN: National Healthcare Safety Network; ARDS: Acute Respiratory Distress Syndrome

\section{Introduction}

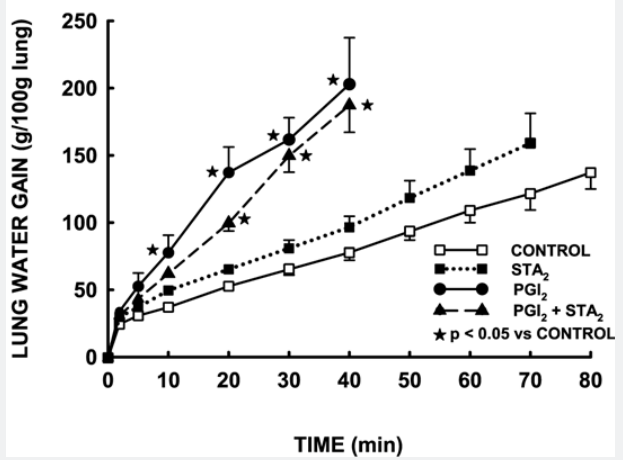

Figure 1: Time course of lung weight gain during elevation of left atrial pressure (CONTROL group), treatment with thromboxane $A_{2}$ analogue (STA ${ }_{2}$ group), treatment with prostacyclin ( $P \mathrm{Fl}_{2}$ group), and treatment with both prostacyclin and thromboxane $\mathrm{A}_{2}$ analogue (PGI - STA ${ }_{2}$ group). In the group treated with thromboxane $\mathrm{A}_{2}$ analogue, the lung weight gain did not differ from the CONTROL group. On the other hand, there were marked increases in lung water gain in the group treated with prostacyclin (either with or without thromboxane $\mathrm{A}_{2}$ analogue). Reproduced with permission from Circ Res (1989) 65: 1409-1416. 
In patients with sepsis, pulmonary edema can develop without left ventricular volume overload. In other words, the presence of radiographic evidences of pulmonary edema may not necessarily indicate the presence of fluid overload in these patients. Animal studies have shown that thromboxane $A_{2}$ activated in sepsis or endotoxemia mediates pulmonary venous vasoconstriction, thus leading to an increase in pulmonary capillary pressure which results in pulmonary edema, without involving changes in capillary permeability or left ventricular volume [1,2]. The pulmonary edema, assessed as the rate of lung weight gain [1] or the increase in lung lymph flow with progressively low lymph/ plasma ratio [2], induced by thromboxane $A_{2}$ was not different from that by the left atrial pressure elevation (Figure 1).

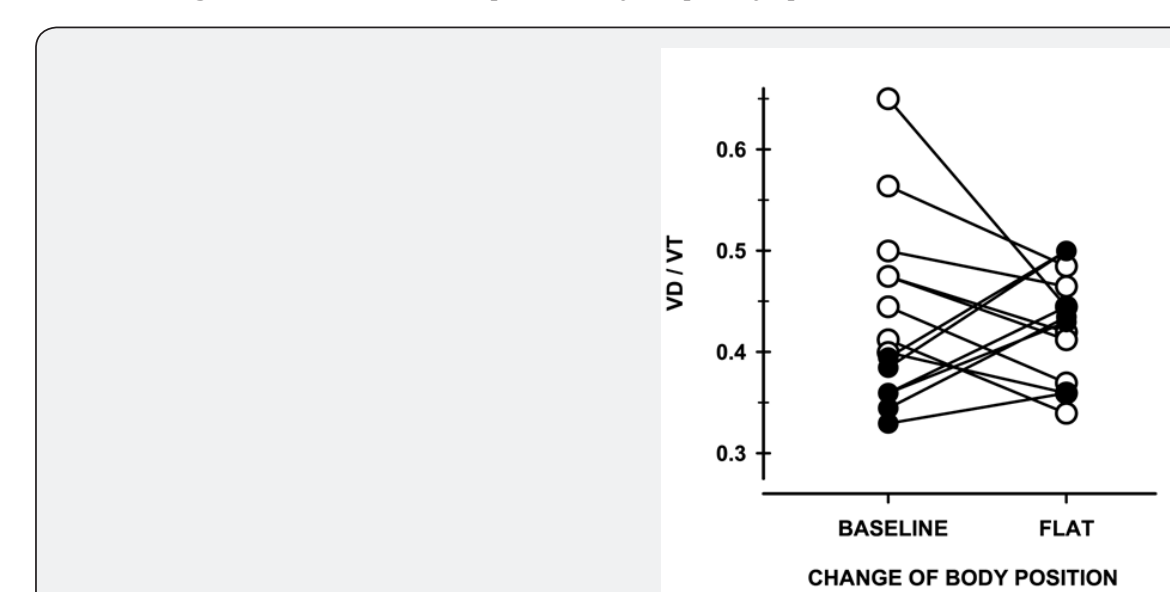

Figure 2: Changes in VD/VT depending on the baseline PASS. The physiologic dead space-to-tidal volume ratio (VD/VT) decreased in eight patients (open circles) with a baseline pulmonary artery systolic storage (PASS) less than 0.65 , when patients were placed in supine position from reverse Trendelenburg position (reflecting increased pulmonary blood volume) but increased in six patients (closed circles) with a baseline pulmonary artery systolic storage higher than 0.65 , when patients were placed in supine position. As shown in Figure 3 , a high baseline pulmonary artery systolic storage indicates the presence of high pulmonary venous resistance. Reproduced with permission from J Surg Res (2013) 185: 310-318.

Moreover, infusion of cyclooxygenase inhibitor, indomethacin or thromboxane receptor antagonist inhibits pulmonary venoconstriction and prevents the development of pulmonary edema [1$3]$. The increase in pulmonary venous resistance during endotoxemia has been well documented previously [4]. Also, it has been shown that in patients with sepsis [5] or with morbid obesity [6], an increase in pulmonary venous resistance contributes to pulmonary artery diastolic-occlusion pressure gradient. Furthermore, a clinical study [7] has shown that when pulmonary blood volume is increased by hydration in patients with sepsis or morbid obesity, only the group of patients with a high pulmonary venous resistance develop the more uneven distribution of ventilation-to-perfusion ratios of the lung (Figure 2), as a result of an increase in non-pulsatile pulmonary capillary blood volume, which can lead to pulmonary edema.

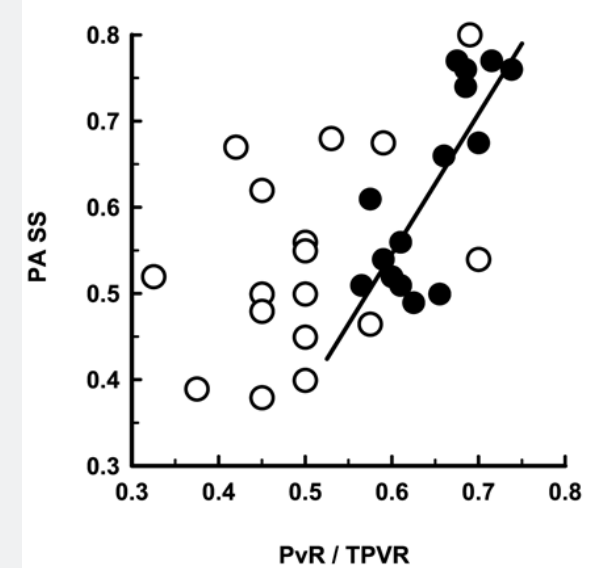

Figure 3: A positive correlation between PASS and PVR/TPVR ratio in patients with a PAD-PCWP gradient higher than $6 \mathrm{mmHg}$ (closed circles). PASS denote pulmonary artery systolic storage (fraction of the portion of right ventricular stroke volume stored in the pulmonary artery during systole and discharged to the pulmonary capillaries during diastole), PvR/TPVR the ratio of pulmonary venous resistance/total pulmonary vascular resistance, and PAD-PCWP gradient pulmonary artery diastolic-occlusion pressure gradient. Data from the previous study on morbid obesity [7] and data from other study on acute respiratory distress syndrome [8] were pooled. Reproduced with permission from J Surg Res (2013) 185: 310-318. 
This study has also shown the presence of a strong correlation between the pulmonary venous resistance and pulmonary artery systolic storage (the fraction of the portion of right ventricular stroke volume stored in the pulmonary artery during systole and discharged to the pulmonary capillaries during diastole) before the pulmonary blood volume is increased (Figure 3). When the pulmonary blood volume is increased, pulmonary artery systolic storage decreases only in the group of patients with a high pulmonary venous resistance, compared with the other group in whom it increases (Figure 4), despite that there is no difference in pulmonary artery occlusion pressure between the two groups.

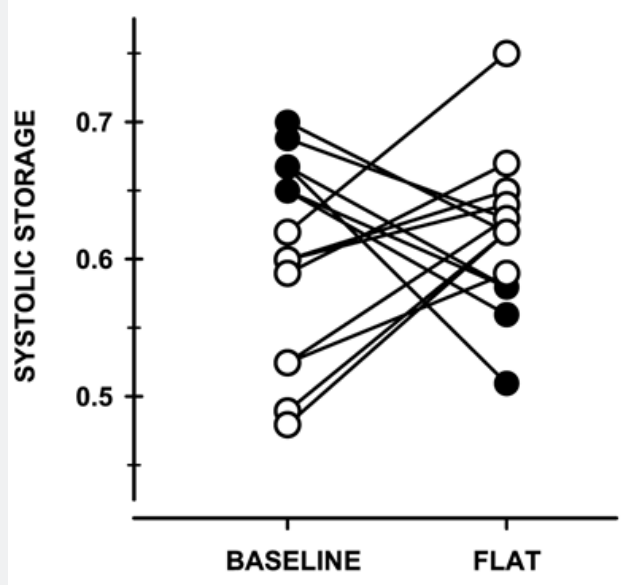

CHANGE OF BODY POSITION

Figure 4: Changes in PASS (pulmonary artery systolic storage) depending on the baseline PASS. Pulmonary artery systolic storage increased in eight patients (open circles) with a baseline pulmonary artery systolic storage less than 0.65 , when patients were placed in supine position (reflecting increased pulmonary blood volume) but decreased in six patients (closed circle) with a baseline pulmonary artery systolic storage higher than 0.65 , when patients were placed in supine position. In patients with a high pulmonary venous resistance, reflected by a high pulmonary artery diastolic-occlusion pressure gradient, the baseline pulmonary artery systolic storage is already high as shown in Figure 3. When pulmonary blood volume is increased, an increase in pulmonary artery systolic storage is much less in this group. This is because pulmonary artery systolic storage is determined by pulmonary artery distensibility and the distensibility of pulmonary artery is already at or near maximum limit in this group. Further increases in pulmonary blood volume would decrease the distensibility, and hence decrease pulmonary artery systolic storage. As a result, pulmonary artery and capil-laries become less pulsatile and distended, prone to develop pulmonary edema as shown in Figure 2. Reproduced with permission from J Surg Res (2013) 185: 310-318.

In support of these findings, an increase in pulmonary artery systolic storage has been shown to be associated with the more even distribution of ventilation-to-perfusion ratios in patients with Acute Respiratory Distress Syndrome (ARDS) [7,8]. As such, this study has clearly demonstrated that the development of acute pulmonary edema does not necessarily indicate left ventricular volume overload during intravascular volume expansion, particularly when pulmonary venous resistance is increased. Without considering the possible presence of the increased pulmonary venous resistance and/or monitoring intravascular volume status, the validation of any definition regarding circulatory overload or sepsis is questionable.

\section{Discussion}

In a previous case-control study [9], in which risk factors and clinical outcomes associated with perioperative Transfusion Associated Circulatory Overload (TACO) were examined, the authors used the National Healthcare Safety Network (NHSN) TACO Definition 2016 to identify cases of TACO [10], without defining the intravascular volume status. This could be problematic because most of criteria in NHSN TACO Definition 2016 (acute respiratory distress, positive fluid balance, elevated brain natriuretic peptide, radio-graphic evidence of pulmonary edema) may well be explained with acute pulmonary edema, caused by the increased pulmonary venous resistance rather than by the left ventricular volume overload. The positive fluid balance during perioperative period does not necessarily indicate the left ventricular fluid overload, because it is impossible to take into account the fluid loss to third space [11] and the fluid loss through the surgical site. The patients could be hypovolemic despite the presence of positive fluid balance. An elevated brain natriuretic peptide levels of less than $400 \mathrm{pg} / \mathrm{mL}$ can be seen in pulmonary embolism [12,13], in which pulmonary artery diastolic-occlusion pressure gradient increases [14], thus indicating the presence of increased pulmonary venous resistance.

Also, according to the results of the study with TACO [9], significantly more patients with TACO had been on $\beta$-adrenergic receptor blocking agent (most likely non-selective) preoperatively than control group. The nonselective $\beta$-blocking agent has been shown to increase pulmonary venous vasoconstriction by blocking $\beta_{2}$ adrenergic vasodilating effect [15]. The $\beta_{2}$ adrenergic vasodilating effect is enhanced particularly when the pulmonary vascular tone is elevated with thromboxane analogue 
(Figure 5) [16]. Thus, in this situation the effect of blocking $\beta_{2}-$ adrenergic receptor by a nonselective $\beta$-blocking agent would be greatly augmented on the pulmonary venous resistance, which can increase pulmonary capillary pressure, leading to acute pulmonary edema. However, one may argue that the possibility of left ventricular depression by nonselective $\beta$-blocking agent cannot be ignored as one of the contributing factors for the development of TACO.

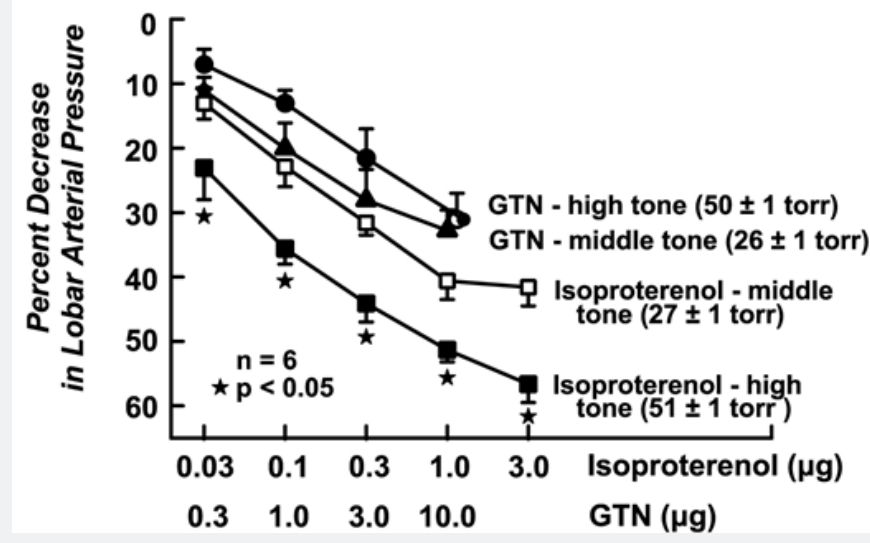

Figure 5: Effects of an increase in vascular tone on vasodilator responses to isoproterenol and nitroglycerin (GTN) in pulmonary vascular bed. Responses were compared at intermediate vascular tone level $(\sim 26 \mathrm{mmHg})$ and under high vascular tone $(\sim 50 \mathrm{mmHg})$ conditions. Vascular tones were elevated with prostaglandin endoperoxide analogue. Star indicates that responses to isoproterenol are significantly greater under high tone conditions when compared with intermediate tone conditions. Percent decrease in lobal arterial pressure on ordinate was calculated as the pressure fall divided by the initial pressure multiplied by 100 . Since thromboxane $A_{2}$ analogue-induced increase in pulmonary venous pressure comprise $82 \%$ of increase in total pulmonary vascular pressure [3], a decrease in lobal arterial pressure indicates mainly a decrease in pulmonary venous pressure. Reproduced with permission from Am $\mathrm{J}$ Physiol (heart Circ Physiol) (1986) 250: H1109-H 1116.

Contrary to this argument, a previous study has shown that preoperative use of nonselective $\beta$-blocking agent, propranolol is not associated necessarily with unacceptable cardiovascular depression on anesthetic management during coronary artery bypass surgery [17]. Thus, it is not likely that the nonselective $\beta$-blocking agent contributed to the development of TACO as its $\beta_{1}$ adrenergic blocking effect on left ventricular function. Although other possibility than the effect of nonselective $\beta$-adrenergic blocking agent may include the effect of thromboxane $\mathrm{A}_{2}$ activated by sepsis or hemorrhagic shock [18], which may have involved in the increased pulmonary venous resistance, the findings that more patients in TACO group had been on nonselective $\beta$-adrenergic blocking medication preoperatively, further support the argument that the increased pulmonary venous resistance contributed to the development of TACO. Taken together, many patients in TACO group may not have had circulatory overload. It would be very difficult to rule out this possibility without monitoring left ventricular filling pressure or volume, even in the situation with a positive fluid balance. The poor outcome in some of the patients with TACO in that study [9] might have been caused by hypovolemia.

Interestingly, prophylactic inhalation of Salmeterol, $\beta_{2}-$ adrenergic agonist has been shown to prevent high-altitude pulmonary edema [19]. Since the increased pulmonary venous resistance, as reflected by the increased pulmonary artery diastolic-occlusion pressure gradient, has been shown in highaltitude mountainers [20,21], the inhalation of Salmeterol may prevent the development of pulmonary edema by decreasing pulmonary venous resistance rather than by enhancing sodiumdependent absorption of fluid. Although the effect of $\beta_{2}$-adrenergic agonist on the enhanced clearance of alveolar fluid has been well known for the resolution of pulmonary edema [22], it is not likely that the enhanced clearance can explain the prevention of highaltitude pulmonary edema.

Moreover, a previous study has shown that the hypoxic pulmonary venoconstriction plays a major role in pulmonary capillary recruitment with an increased pulmonary capillary blood volume in response to hypoxia in healthy humans [23], which further supports the above notion regarding the effects $\beta_{2}$-adrenergic agonist on pulmonary venoconstriction in highaltitude pulmonary edema. The effect of inhaled of $\beta_{2}$-adrenergic agonist for the prevention of ARDS has been studied in patients undergoing esophagectomy as a multicenter randomized controlled trial [24]. In this study, although the incidence of ARDS did not differ between study and placebo group, postoperative adverse events were less frequent in the study group.

In this study, unfortunately, pulmonary artery catheter was not used. This study could have shown that the inhalation of $\beta_{2}$-adrenergic agonist would have benefited in patients with an increased pulmonary venous resistance (pulmonary artery diastolic-occlusion pressure gradient $>6 \mathrm{mmHg}$ ), for the prevention or reduction of the incidence of ARDS. The low pulmonary venous resistance would keep the lung water level low, regardless of whether the pulmonary edema is a permeability type or pressurized type. Vasodilator, prostacyclin has been shown to decrease pulmonary venoconstriction slightly but 
increase pulmonary capillary pressure and permeability, resulting in an increase in thromboxane $\mathrm{A}_{2}$-induced pulmonary edema despite a decrease in pulmonary arterial pressure (Figure 1) $[1,3]$, suggesting that it may not be possible to reduce pulmonary edema without lowering pulmonary venous resistance in sepsis. This notion is consistent with the previous report [25] which showed the limited effect of inhaled prostacyclin in treating ARDS. Also, inhaled nitric oxide has been shown not effective in improving oxygenation in majority of patients with septic shock [26], suggesting that nitric oxide is not capable to overcome thromboxane $\mathrm{A}_{2}$-induced pulmonary venoconstriction.

Actually, when pulmonary vascular tone is increased by thromboxane $A_{2}$ analogue, the response of $\beta_{2}$-adrenergic receptor of pulmonary vein to the vasodilating effect of the $\beta_{2}$-receptor agonist is greatly enhanced, but the response to nitroglycerin is not enhanced as shown in Figure 5 [16]. It is most likely that nitric oxide may be able to reduce hypoxia-induced pulmonary venoconstriction, but not endotoxin-induced venoconstriction. Thus, the $\beta_{2}$-adrenergic receptor agonist such as Salmeterol should provide a great potential in decreasing pulmonary venous resistance, and hence improving pulmonary edema in patients with ARDS/sepsis.

Lately a new definition of sepsis and septic shock (Sepsis-3) [27-29], has been published with controversies. According to this definition, septic shock should be defined as a subset of sepsis in a clinical situation, in which patients with sepsis require a vasopressor to maintain a mean arterial pressure of $65 \mathrm{mmHg}$ or greater and patients' serum lactate level is greater than $2 \mathrm{mmol} / \mathrm{L}$ in the absence of hypovolemia. However, the problem with this definition is that the adequacy of intravascular volume expansion to over-come hypotension in patients with septic shock was not defined at all in most cases included.

Possibility that the radiographic appearance of acute pulmonary edema caused by the increased pulmonary venous resistance rather than by the left ventricular overload may have contributed to less aggressive efforts of intravascular volume expansion, thus leading to hypovolemia in many cases, cannot be excluded. Thus, in the situation with no definition of intravascular volume status, the interpretation of the retrospectively collected data and the new definition of septic shock (Sepsis-3) based on the progression of sepsis are hardly acceptable concept with a questionable validity. The organ failure and lactic acidemia in some of their cases may have been caused by hypovolemic vasoconstriction or ischemia, probably owing to an inadequate resuscitation, rather than by progression of sepsis alone. This argument is supported by the findings of a recent study in which most of septic patients with hyperlactemia had evidences of hypoperfusion [30].

\section{Conclusion}

In conclusion, an increase in pulmonary venous resistance in perioperative period and/or in sepsis can contribute to the development of acute pulmonary edema in the absence of left ventricular volume over-load. Any attempt to reduce intravascular volume in effort to reduce lung water can result in hypovolemia in this situation. The $\beta_{2}$-adrenergic receptor agonist, which can reduce pulmonary venoconstriction induced by both hypoxia and endotoxemia, would be able to keep lung water level low.

\section{Conflicts of Interest}

There was no financial support for this study from any sources. There was no Institutional or Departmental fund.

\section{References}

1. Yoshimura K, Tod ML, Pier KG, Rubin LJ (1989) Effects of a thromboxane $\mathrm{A}_{2}$ analogue and prostacyclin on lung fluid balance in newborn lambs. Circ Res 66(2): 1409-1416.

2. Ogletree ML, Brigham KL (1980) Arachidonate raises vascular resistance but not permeability in lungs of awake sheep. J Appl Physiol 48(4): 581-586

3. Yoshimura K, Tod ML, Pier KG, Rubin LJ (1989) Role of venoconstriction in thromboxane induced pulmonary hypertension and edema in lambs. J Appl Physiol 66(2): 929-935.

4. Parker RE, Brigham KL (1987) Effects of endotoxemia on pulmonary vascular resistances in unanesthetized sheep. J Appl Physiol 63(3): 1058-1062.

5. Her C, Mandy S, Bairamian M (2005) Increased pulmonary venous resistance contributes to increased pulmonary artery diastolicpulmonary wedge pressure gradient in acute respiratory distress syndrome. Anesthesiology 102(3): 574-580.

6. Her C, Cerabona T, Back SH, Shin SW (2110) Elevated pulmonary venous resistance in morbid obesity: Clinical utility of pulmonary artery catheter. Anesthesiology 113(3): 552-559.

7. Her C, Kim YH, Jeon SY (2013) Changes in pulmonary blood volume changes pulmonary artery systolic storage. J Surg Res 185(1): 310-318.

8. Her C, Baek SH, Shin SW, Lee HJ (2011) Increases in pulmonary artery systolic storage associated with improved ventilation-to-perfusion ratios in acute respiratory distress syndrome. J Crit Care 26(3): 234240.

9. Clifford L, Jia Q, Subramanian A, Yadav H, Schroeder DR, et al. (2017) Risk factors and clinical outcomes associated with perioperative transfusion-associated circulatory overload. Anesthesiology 126(3): 409-418.

10.(2016) The National Healthcare Safety Network, Biovigilance Component, Hemovigilance Component Surveillance Protocol.

11. Mayberry JC, Welker KJ, Goldman RK, Mullins RJ (2003) Mechanism of acute ascites formation after trauma resuscitation. Arch Surg 138(7): 773-776.

12. Maisel A (2002) B-type natriuretic peptide levels: diagnostic and prognostic in congestive heart failure. Circulation 105(20): 2328-2331.

13. Cavallazzi R, Nair A, Vasu T, Marik PE (2008) Natriuretic peptides in acute pulmonary embolism: a systemic review. Intensive Care Med 34(12): 2147-2156.

14. Cozzi PJ, Hall JB, Schmidt GA (1995) Pulmonary artery diastolicocclusion pressure gradient is increased in acute pulmonary embolism. Crit Care Med 23(9): 1481-1484.

15. Barman SA (1995) Effect of catecholamine on pulmonary circulation at elevated vascular tone. J Appl Physiol 78(4): 1452-1458.

16. Hyman AL, Kadowitz PJ (1986) Enhancement of $\alpha$ - and $\beta$ - adrenoceptor responses by elevations in vascular tone in pulmonary circulation. Am J Physiol (Heart Circ Physiol) 250(19): H1109-H1116. 
17. Sill JC, Nugent M, Moyer TP, Torres LE, Schaff HV, et al. (1984) Influence of propranolol plasma levels on hemodynamics during coronary artery bypass surgery. Anesthesiology 60(5): 455-463.

18. Meng ZH, Dyer K, Billiar TR, Tweardy DJ (2001) Essential role for IL-6 in post resuscitation inflammation in hemorrhagic shock. Am J Physiol Cell Physiol 280(2): C343-C351.

19. Sartori C, Allemann Y, Duplain H, Lepori M, Egli M, et al. (2002) Salmeterol for the prevention of high-altitude pulmonary edema. N Engl J Med 346(21): 1631-1636.

20. Lupi Herrera E, Seone M, Sandoval J, Casanova JM, Bialostozky D (1980) Behavior of the pulmonary circulation in the grossly obese patient. Pathogenesis of pulmonary arterial hypertension at an altitude of 2,240 meters. Chest 78(4): 553-558.

21. Maggiorini M, Mélot C, Pierre S, Pfeiffer F, Greve I (2001) High-altitude pulmonary edema is initially caused by an increase in capillary pressure. Circulation 103(16): 2078-2083.

22. Frank JA, Wang Y, Osorio O, Matthay MA (2000) $\beta$-Adrenergic agonist therapy accelerates the resolution of hydrostatic pulmonary edema in sheep and rats. J Appl Physiol 89(4): 1255-1265.

23. Taylor BJ, Kjaergaard J, Snyder EM, Olson TP, Johnson BD (2011) Pulmonary capillary recruitment in response to hypoxia in healthy humans: a possible role for hypoxic pulmonary venoconstriction? Respir Physiol Neurobiol 177(2): 98-107.
24. Perkins GD, Gates S, Park D, Gao F, Knox C, et al. (2014) The beta agonist lung injury prevention. A randomized controlled trial. Am J Respir Crit Care Med 189(6): 674-683.

25. Searcy RJ, Morales JR, Ferreira JA, Johnson DW (2015) The role of inhaled prostacyclin in treating acute respiratory distress syndrome. Ther Adv Respir Dis 9(6): 302-312.

26. Manktelow C, Bigatello LM, Hess D, Hurford WE (1997) Physiologic determinants of the response to inhaled nitric oxide in patients with acute respiratory distress syndrome. Anesthesiology 87(2): 297-307.

27. Seymour CW, Liu VX, Iwashyna TJ, Brunkhorst FM, Rea TD, et al. (2016) Assessment of clinical criteria for sepsis. For the third international consensus definitions for sepsis and septic shock (Sepsis-3). JAMA 315(8): 762-774

28. Shankar Hari M, Phillips GS, Levy ML, Seymour CW, Liu VX, et al. (2016) Developing a new definition and assessing new clinical criteria for septic shock. For the third international consensus definitions for sepsis and septic shock (Sepsis-3). JAMA 315(8): 775-787.

29. Singer M, Deutschman CS, Seymour CW, Shankar Hari M, Annane D, et al. (2016) The third international consensus definitions for sepsis and septic shock (Sepsis-3). JAMA 315(8): 801-810.

30. Alegría L, Vera M, Dreyse J, Castro R, Carpio D, et al. (2017) A hypoperfusion context may aid to interpret hyperlactemia in sepsis-3 septic shock patients: a proof-of-concept study. Ann Intensive Care $7(1): 29-35$

\section{Your next submission with Juniper Publishers will reach you the below assets}

- Quality Editorial service

- Swift Peer Review

- Reprints availability

- E-prints Service

- Manuscript Podcast for convenient understanding

- Global attainment for your research

- Manuscript accessibility in different formats

( Pdf, E-pub, Full Text, Audio)

- Unceasing customer service

Track the below URL for one-step submission https://juniperpublishers.com/online-submission.php 